\title{
Ischaemic heart disease: association with haematocrit in the British Regional Heart Study
}

\author{
Goya Wannamethee, A G Shaper, P H Whincup
}

\begin{abstract}
Objectives - To assess the relationship between haematocrit and risk of major ischaemic heart disease events.

Design - Prospective study of a cohort of men followed up for 9.5 years.

Setting - General practices in 24 towns in England, Wales, and Scotland (British Regional Heart Study).

Subjects - Altogether 7735 men aged 4059 years at screening, who were selected at random from one general practice in each of 24 towns, were studied.

Main outcome measures - Fatal and nonfatal ischaemic heart disease events.

Results - Risk of major ischaemic heart disease events was significantly increased at haematocrit levels of $\geqslant 46.0 \%$. Men with raised haematocrit $(\geqslant 46.0 \%)$ showed a $30 \%$ increase in relative risk (RR) of major ischaemic heart disease events $(R R=1 \cdot 32 ; 95 \%$ confidence intervals (CI) $1 \cdot 10,1 \cdot 57, p<0.01$ ) compared with those with values below $46.0 \%$, even after adjustment for age, social class, smoking, body mass index, physical activity, blood cholesterol, lung function $\left(F E V_{1}\right)$, and pre-existing evidence of ischaemic heart disease. Further adjustment for systolic blood pressure reduced the risk slightly $(R R=1 \cdot 27 ; 95 \%$ CI $1 \cdot 06,1 \cdot 51$, $p=0.02$ ) but it remained significant. The relationship was seen in men with and without pre-existing evidence of ischaemic heart disease. The study suggests that an increased haematocrit level plays a part in the development of major ischaemic heart disease events.
\end{abstract}

( $\mathcal{F}$ Epidemiol Community Health 1994;48:112-118)

Patients with polycythaemia rubra vera who have a noticeably raised haematocrit level experience an increased risk of ischaemic heart disease (IHD). ${ }^{1}$ This may be a consequence of the influence of haematocrit on blood viscosity. ${ }^{23}$ Recent evidence also suggests that the plasma component of viscosity may play a role in the development of atherosclerosis. ${ }^{4}$ However, population studies examining the relationship between haematocrit or haemoglobin and major IHD events have been inconclusive. Most studies have reported a positive association between haematocrit or haemoglobin (which are highly correlated) and the risk of heart attacks, ${ }^{5-12}$ and some of these have found the association to be independent of the coronary risk factors..$^{6-8}$ Other studies have found the relationship to be dependent on established cardiovascular risk factors, for example smoking, blood pressure, and blood cholesterol, ${ }^{10}{ }^{12}$ and others have reported no association..$^{13-14}$ In most of these studies a linear relationship between haematocrit and outcome has been assumed. A recent study, however, has shown a significantly increased risk of heart attacks in subjects with levels above $46.0 \%$ compared with those with values below this, independent of the recognised risk factors. ${ }^{8}$ This suggests that the relationship may not be linear and that risk may be increased only above certain threshold levels of haematocrit. This study examines the relationship between haematocrit and risk of major IHD events in a large prospective study of middle-aged men, and focuses on the role of cardiovascular risk factors in the relationship between ischaemic heart disease and haematocrit.

\section{SUBJECTS AND METHODS}

The British Regional Heart Study is a large prospective study of cardiovascular disease comprising 7735 men aged 40-59 years selected from the age-sex registers of one group general practice in each of 24 towns in England, Wales, and Scotland. The criteria for selecting the town, the general practice, and the subjects as well as the methods of data collection, have been reported. ${ }^{15}$ Research nurses administered to each man a standard questionnaire that included questions on smoking habits, alcohol intake, physical activity, and medical history. Several physical measurements were made. Classification methods for smoking status, alcohol consumption, occupation (social class), and body mass index (BMI) have been reported..$^{16}$ Obesity is defined as a $B M I \geqslant 28 \mathrm{~kg} / \mathrm{m}^{2}$, the top $20 \%$ of the distribution in these men. The men were asked to indicate their usual pattern of physical activity, under the headings of regular walking or cycling, recreational (weekend) activity, and active physical exercise. A physical activity (exercise) score was derived for each man based on the frequency and type (intensity) of the physical activity. Full details of the derivation of the score have been described. ${ }^{16}$ The men were grouped into six broad categories based on their total score: inactive, occasional, light, moderate, moderately-vigorous, and vigorous. Those engaged in at least moderate levels of physical activity were classified as active.

\section{HAEMATOCRIT}

Blood samples (non-fasting) were taken for measurement of biochemical and haematologi- 
cal variables. All samples reached the Department of Haematology, Queen Elizabeth Hospital, Birmingham by the following morning and estimations were completed by noon of that day. Haematocrit was estimated using a Coulter S electronic particle counter (Coulter Electronics Ltd, Luton) calibrated daily with Coulter \$C. Internal quality control was achieved using an algorithm based on patientderived haematology data, modified from Bull et $\mathrm{al},{ }^{17}$ and external quality assurance by participation in the National External Quality Assurance Scheme (NEQAS).

Haematocrit and haemoglobin concentration were strongly correlated $(r=0.93)$ and only the haematocrit findings are presented in this paper. The men were divided into five groups based on levels of haematocrit: $<42 \cdot 0 \%=1218 \mathrm{men}, 42 \cdot 0-43 \cdot 9 \%=1648 \mathrm{men}$, $44 \cdot 0-45 \cdot 9 \%=2018$ men, $46 \cdot 0-47 \cdot 9 \%=1414$ men, and $\geqslant 48 \cdot 0 \%=1048$ men.

\section{SERUM PROTEIN}

Thirteen biochemical factors, including albumin and globulin, were measured on serum with a Technicon SMA 12/60 "Autoanalyzer". Total serum protein was defined as albumin + globulin concentrations. No measurement of fibrinogen was available.

\section{BLOOD PRESSURE}

The men attended the examination centre over a 10 hour period between 8.30 am and $6.30 \mathrm{pm}$ on weekdays and were not asked to fast or to abstain from alcohol beforehand. The London School of Hygiene sphygmomanometer was used to measure blood pressure twice in succession, using a standard adult cuff on the right arm of all subjects and with the subjects seated and the arm supported on a cushion. The mean of the two readings was used in the analysis and all blood pressure readings were adjusted for observer variation within each town. ${ }^{18}$

\section{PRE-EXISTING IHD}

The men were asked whether a doctor had ever told them that they had angina or myocardial infarction (heart attack, coronary thrombosis), stroke, and a number of other disorders. The WHO (Rose) chest pain questionnaire was administered to all men at the initial examination $^{19}$ and a three-orthogonal lead electrocardiogram was recorded at rest and analysed by computer in the Department of Medical Cardiology, Glasgow Royal Infirmary. Men with evidence of IHD were defined as those with a recall of doctor diagnosis of angina or heart attack, WHO (Rose) questionnaire responses indicating angina (definite or possible) or possible myocardial infarction, or electrocardiographic evidence of definite or possible myocardial ischaemia or myocardial infarction. Definite myocardial infarction is defined as men with recall of a doctor diagnosis of a myocardial infarction or evidence of definite myocardial infarction on electrocardiogram.
FOLLOW UP

All men have been followed up for all cause mortality and for cardiovascular morbidity for 9.5 years. ${ }^{20}$ Information on death was collected through the established "tagging" procedures provided by the National Health Service registers in Southport (England and Wales) and Edinburgh (Scotland). Fatal IHD events included all deaths with ischaemic heart disease as the underlying cause (International Classification of Disease, 9 th revision, codes 410-414) which occurred during the period of follow up, irrespective of non-fatal events which may have preceded the fatal event during the follow up period. A non-fatal heart attack was one which satisfied at least two of the following WHO criteria: (a) preceded by severe prolonged chest pain, (b) electrocardiographic evidence of myocardial infarction, (c) cardiac enzyme changes associated with myocardial infarction.

\section{STATISTICAL METHODS}

Multiple logistic regression was used to obtain the relative risks for the five haematocrit groups adjusted for age, smoking, social class, physical activity, body mass index, lung function, pre-existing IHD, blood cholesterol, and systolic blood pressure. Age, body mass index, lung function, blood cholesterol, and systolic blood pressure were fitted as continuous variables, smoking as four dummy variables (never, ex-smokers, light, moderate, and heavy), and social class as two dummy variables (manual, non-manual, and Armed Forces). Haematocrit was fitted as four dummy variables for the five haematocrit groups and in some of the analyses as one dummy variable ( $\geqslant 46 \% v$ the rest). Fitting haematocrit as five categorical groups makes no assumptions of a linear relationship between haematocrit and risk of major IHD events.

\section{Results}

Data on haematocrit were available on 7346 men with a mean (SD) of $44.47 \%$ (3.16\%), range $25-63 \%$. During the follow up period of 9.5 years in these 7346 men there were 580 major IHD events (non-fatal heart attacks and all IHD deaths including sudden cardiac death).

\section{HAEMATOCRIT AND RISK OF MAJOR IHD EVENTS}

Figure 1 shows the crude heart attack rate/ $1000 /$ year by the five haematocrit groups in all men. There was little difference in risk of major IHD events in men with haematocrit levels below $46 \cdot 0 \%$. Risk was significantly increased at levels of $46.0 \%$ and above. A global test for overall difference between the five groups was significant $(p<0.001)$.

\section{HAEMATOCRIT AND CORONARY RISK FACTORS}

Table 1 shows the relationship between the five haematocrit groups and factors associated 


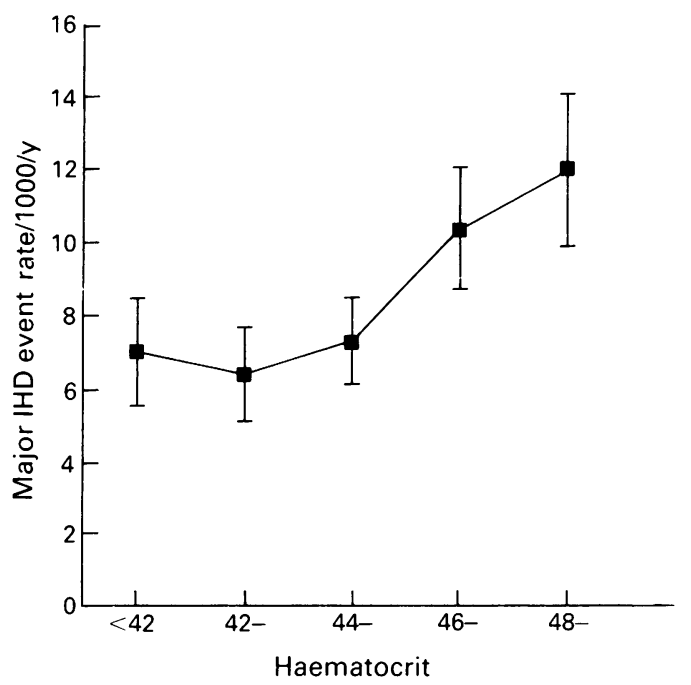

Figure 1 Major ischaemic heart disease (IHD) event rate $1000 /$ year with $95 \%$ confidence interval in relation to the five haematocrit groups.

with the risk of major IHD events. There was no consistent association with age or with social class. Smoking, BMI, and obesity were strongly associated with haematocrit $(p<0.0001)$. Physical activity showed a small but significant inverse relationship $(\mathrm{p}<0.0001)$. Forced expiratory volume in one second $\left(\mathrm{FEV}_{1}\right)$ decreased significantly with increasing haematocrit $(p<0.0001)$.

HAEMATOCRIT AND PRE-EXISTING DISEASE

Table 1 also shows the relationship between haematocrit and presence of pre-existing IHD and diabetes. The prevalence of pre-existing IHD and definite myocardial infarction increased significantly with increasing haematocrit. Diabetes was somewhat more prevalent in the lowest haematocrit group but there was no consistent relationship in the other groups.
HAEMATOCRIT, BLOOD LIPIDS, AND BLOOD PRESSURE

Table 1 shows the relationship between haematocrit and systolic and diastolic blood pressure, blood cholesterol, triglyceride, high density lipoprotein (HDL) cholesterol, and blood glucose. There was a strong positive relationship between haematocrit and both systolic and diastolic blood pressure, cholesterol, and triglyceride. No association was seen with HDL cholesterol or with non-fasting blood glucose concentrations. The strong positive association between haematocrit and systolic and diastolic blood pressure, blood cholesterol, and triglyceride persisted after adjustment for age, social class, BMI, and smoking (data not shown).

\section{IS RAISED HAEMATOCRIT AN INDEPENDENT RISK} FACTOR?

Because of the suggestion that low levels of haematocrit may also be associated with higher risk $^{7}$ and that the lowest risk in this study was seen in those with haematocrit levels of $42 \cdot 0-43.9 \%$, this group has been used as the base group for comparative purposes. The relationship between haematocrit and the risk of a major IHD event was examined adjusting first for age only (table 2, column A) and then, in addition, for age, social class, smoking, physical activity, and BMI (table 2, column B). This latter adjustment reduced the increased risk seen at raised haematocrit values $(\geqslant 46.0 \%)$ but it remained significant. After these adjustments, there was no further increase in risk of major IHD events at higher levels of haematocrit. Additional adjustment for $\mathrm{FEV}_{1}$, diabetes and presence of IHD (column $\mathrm{C}$ ) reduced the risk further but a raised haematocrit $(\geqslant 46.0 \%)$ was still associated with a significant increased risk compared with those below $46.0 \%$.

In this study, triglyceride is not an independent risk factor once blood cholesterol has been taken into account. ${ }^{21}$ Triglyceride has not therefore been included in the adjustments in

Table 1 Haematocrit and coronary risk factors, blood pressure, and blood lipids

\begin{tabular}{|c|c|c|c|c|c|c|}
\hline & \multicolumn{5}{|l|}{ Haematocrit } & \multirow[b]{2}{*}{$\begin{array}{l}\text { Trend, } \\
\text { p value }\end{array}$} \\
\hline & $\begin{array}{l}<42 \\
(n=1218)\end{array}$ & $\begin{array}{l}42- \\
(n=1648)\end{array}$ & $\begin{array}{l}44- \\
(n=2018)\end{array}$ & $\begin{array}{l}46- \\
(n=1414)\end{array}$ & $\begin{array}{l}48- \\
(n=1048)\end{array}$ & \\
\hline $\begin{array}{l}\text { Mean age (y) } \\
\text { Manual work (\%) }\end{array}$ & $\begin{array}{l}50 \cdot 7 \\
63\end{array}$ & $\begin{array}{l}50 \cdot 0 \\
56\end{array}$ & $\begin{array}{l}50 \cdot 1 \\
56\end{array}$ & $\begin{array}{l}50 \cdot 1 \\
57\end{array}$ & $\begin{array}{l}50 \cdot 7 \\
58\end{array}$ & $\begin{array}{l}\text { NS } \\
\text { NS }\end{array}$ \\
\hline Smoking: & & & & & & \\
\hline Never (\%) & 30 & 27 & 24 & 20 & 14 & *** \\
\hline $\begin{array}{l}\text { Ex-smoker }(\%) \\
\text { Current }(\%)\end{array}$ & 40 & 40 & 37 & 33 & 25 & **** \\
\hline $\begin{array}{l}\text { Current }(\%) \\
\text { Physical activity: }\end{array}$ & 30 & 33 & 39 & 47 & 61 & *** \\
\hline $\begin{array}{l}\text { Physical activity: } \\
\text { Inactive }(\%)\end{array}$ & & & & $9 \cdot 6$ & 13.0 & *** \\
\hline $\begin{array}{l}\text { Active (\%) } \\
\text { Ans }\end{array}$ & 39 & 41 & 35 & 36 & 23 & *** \\
\hline Mean BMI & 24.9 & $25 \cdot 2$ & $25 \cdot 7$ & $25 \cdot 6$ & $26 \cdot 2$ & $* * * *$ \\
\hline Obese (\%) & 15 & 16 & 21 & $\begin{array}{c}20 \\
33 \cdot 5\end{array}$ & $\begin{array}{l}27 \\
313 \cdot 1\end{array}$ & ${ }_{* * * *}^{* * *}$ \\
\hline $\begin{array}{l}\text { Mean FEV } \\
\text { Pre-existing disease (\%): }\end{array}$ & $341 \cdot 1$ & $340 \cdot 8$ & $333 \cdot 2$ & 330.5 & $313 \cdot 1$ & ** \\
\hline $\begin{array}{l}\text { Pre-existing disease }(\%) \text { : } \\
\text { Definite myocardial infarction }\end{array}$ & & & $5 \cdot 6$ & 6.9 & $7 \cdot 4$ & $* *$ \\
\hline Any ischaemic heart disease (\%) & 24 & 22 & 24 & 27 & & ** \\
\hline $\begin{array}{l}\text { Diabetes }(\%) \\
\text { (\%) }\end{array}$ & $2 \cdot 6$ & 1.3 & 1.5 & $1 \cdot 1$ & $1 \cdot 2$ & NS \\
\hline Mean systolic blood pressure & $141 \cdot 4$ & 143.5 & 145.2 & $147 \cdot 0$ & 149.8 & $* * *$ \\
\hline Mean diastolic blood pressure & $78 \cdot 3$ & $80 \cdot 8$ & 82.5 & $84 \cdot 2$ & $86 \cdot 3$ & $* * *$ \\
\hline Mean cholesterol & 6.01 & $6 \cdot 25$ & 6.32 & 6.42 & 6.54 & $* * *$ \\
\hline Mean triglyceride & 1.52 & 1.67 & 1.73 & 1.82 & $2 \cdot 01$ & $* * *$ \\
\hline Mean HDL cholesterol & $1 \cdot 16$ & $1 \cdot 17$ & $1 \cdot 14$ & $1 \cdot 15$ & 1.13 & NS \\
\hline Mean glucose & $5 \cdot 52$ & $5 \cdot 47$ & $5 \cdot 47$ & $5 \cdot 47$ & 5.52 & NS \\
\hline
\end{tabular}


Table 2 Haematocrit and adjusted relative risk ( $R R$ ) (95\% confidence interval) of major ischaemic heart disease (IHD) events

\begin{tabular}{|c|c|c|c|c|c|c|c|}
\hline \multirow{2}{*}{$\begin{array}{l}\text { Haematocrit } \\
\text { level }\end{array}$} & \multirow{2}{*}{$\begin{array}{l}\text { No of } \\
\text { men }\end{array}$} & \multirow{2}{*}{$\begin{array}{l}\text { No of } \\
\text { IHD } \\
\text { cases }\end{array}$} & \multicolumn{5}{|c|}{ Adjusted RRs } \\
\hline & & & $A$ & $B$ & $C$ & $D$ & $E$ \\
\hline $\begin{array}{l}<42 \\
42- \\
44- \\
46- \\
48-\end{array}$ & $\begin{array}{l}1218 \\
1648 \\
2018 \\
1414 \\
1048\end{array}$ & $\begin{array}{r}82 \\
100 \\
139 \\
140 \\
119\end{array}$ & $\begin{array}{l}1.06 \\
1.00 \\
1.15 \\
1.75 \\
1.92 \\
p<0.0001\end{array}$ & $\begin{array}{l}1.06(0.79,1.43) \\
1.00 \\
1.08(0.84,1.40) \\
1.55(1 \cdot 17,2.05) \\
1.55(1.17,2.05) \\
p<0.0001\end{array}$ & $\begin{array}{l}1.01(0.73,1.39) \\
1.00 \\
1.00(0.76,1.32) \\
1.42(1.06,1 \cdot 90) \\
1.35(1.01,1.82) \\
p<0.001\end{array}$ & $\begin{array}{l}1.07(0.68,1.48) \\
1.00 \\
0.97(0.74,1.30) \\
1.36(1.05,1.80) \\
1.25(0.93,1.68) \\
p=0.003\end{array}$ & $\begin{array}{l}1.09(0.79,1.49) \\
1.00 \\
0.95(0.72,1.39) \\
1.31(1.00,1.73) \\
1.17(0.87,1.58) \\
p=0.02\end{array}$ \\
\hline Relative risk & & $\% v$ rest & 1.70 & $1 \cdot 48(1 \cdot 23,1 \cdot 77)$ & $1 \cdot 40(1 \cdot 17,1 \cdot 67)$ & $1 \cdot 32(1 \cdot 10,1 \cdot 57)$ & $1.27(1.06,1.51)$ \\
\hline
\end{tabular}

(A) Age adjusted.

(B) Adjusted for age, body mass index, social class, smoking, and physical activity.

C) Adjusted for $(\mathrm{B})$ and pre-existing ischaemic heart disease, diabetes, and forced expiratory volume in one second.

(D) Adjusted for (C) and in addition for blood cholesterol.

(E) Adjusted for (D) and in addition for systolic blood pressure.

addition to blood cholesterol. Since blood pressure may be a mediating factor between haematocrit and the risk of a major IHD event, we have further adjusted, first in addition for blood cholesterol (table 2, column D) and then in addition for systolic blood pressure (table 2, column E). Adjustment for blood cholesterol reduced the increased risk of ischaemic heart disease seen in those with raised haematocrit $(\geqslant 46.0 \%$ ), but the risk nevertheless increased significantly at levels of $46.0 \%$ or above. Adjustment for systolic blood pressure reduced the increased risk of major IHD events even further but a raised haematocrit $(\geqslant 46.0 \%)$ was still associated with a significant increase in risk. Since those with low haematocrit $(<42.0 \%)$ had the lowest blood pressures and blood cholesterol concentrations, adjustment for these factors increased the risk slightly in these men.

\section{PRE-EXISTING IHD}

Since the presence of IHD may be associated with an increase in haematocrit levels (table 1) and it has been recognised that haematocrit is raised in patients with $\mathrm{IHD},{ }^{22-24}$ we have examined the relationship between haematocrit and IHD separately in men with and without pre-existing IHD. Table 3 shows the rate/ 1000 /year and the relative risk of a major IHD event for each of the five haematocrit groups adjusted for age, smoking, social class, physical activity, BMI, lung function $\left(\mathrm{FEV}_{1}\right)$, and diabetes (column A), in men with and without evidence of pre-existing IHD. In both groups of men, the risk of major IHD increased at levels at and above $46.0 \%$, even after these adjustments - that is, $\geqslant 46.0 \% \quad v$ the rest.
Additional adjustment for blood cholesterol (column B) and systolic blood pressure (column $C$ ) reduced the excess risk slightly and increased slightly the risk seen in those with low haematocrit $(<42 \cdot 0 \%)$. In men with no pre-existing IHD, those with haematocrit levels $\geqslant 46 \%$ showed significantly higher risk than those with levels below even after these adjustments, although risk seemed to decline in those in the highest haematocrit group $(\geqslant 48 \%)$. In those with pre-existing IHD, increased risk was present but was not statistically significant.

\section{POSSIBLE INTERACTIONS}

We have also explored possible interactions between haematocrit, smoking, systolic blood pressure, and blood cholesterol with the risk of IHD. Figure 2 shows the adjusted relative risk of major IHD events in relation to the two haematocrit groups ( $\geqslant 46.0 \%$ and $<46.0 \%$ ) plotted on a log scale by smoking, systolic blood pressure, and blood cholesterol concentration. Within all smoking, systolic blood pressure, and blood cholesterol categories, raised haematocrit $(\geqslant 46.0 \%)$ showed higher risk than those with levels below $46.0 \%$ (figure 2 ). The effect was similar at all levels of these risk factors and there was no evidence of an interaction.

\section{HAEMATOCRIT AND SERUM PROTEIN}

It is well established that haematocrit is an important determinant of blood viscosity. ${ }^{3}$ Since circulatory protein is also a major determinant of blood viscosity, we examined whether total serum protein is related to haem-

Table 3 Haematocrit and adjusted relative risk ( $R R$ ) (95\% confidence interval) of major ischaemic heart disease (IHD) events in men with and without pre-existing IHD

\begin{tabular}{|c|c|c|c|c|c|c|c|c|c|c|}
\hline \multirow{3}{*}{$\begin{array}{l}\text { Haematocrit } \\
\text { level }\end{array}$} & \multicolumn{5}{|c|}{ No evidence of IHD } & \multicolumn{5}{|c|}{ Pre-existing evidence of IHD } \\
\hline & \multirow[b]{2}{*}{ No } & \multirow[b]{2}{*}{ Rate $/ 1000 / y$} & \multicolumn{3}{|l|}{$R R$} & \multirow[b]{2}{*}{ No } & \multirow[b]{2}{*}{ Rate $/ 1000 / y$} & \multicolumn{3}{|l|}{$R R$} \\
\hline & & & $A$ & $B$ & $C$ & & & $A$ & $B$ & $C$ \\
\hline $\begin{array}{l}<42 \\
42- \\
44- \\
46- \\
48- \\
\geq 46 \% \text { v rest }\end{array}$ & $\begin{array}{r}922 \\
1292 \\
1528 \\
1030 \\
723\end{array}$ & $\begin{array}{l}5 \cdot 0(44) \\
4 \cdot 7(58) \\
4 \cdot 9(71) \\
8 \cdot 2(80) \\
7 \cdot 6(52) \\
\mathrm{p}<0 \cdot 0001\end{array}$ & $\begin{array}{l}1.00 \\
1.00 \\
0.96 \\
1.63 \\
1.27 \\
p=0.002\end{array}$ & $\begin{array}{l}1 \cdot 10 \\
1.00 \\
0.94 \\
1.54 \\
1.16 \\
p=0.01\end{array}$ & $\begin{array}{l}1 \cdot 13(0 \cdot 74,1 \cdot 58) \\
1.00 \\
0.93(0 \cdot 65,1 \cdot 34) \\
1.48(1.02,2 \cdot 10) \\
1 \cdot 15(0 \cdot 74,1 \cdot 65) \\
p=0.04\end{array}$ & $\begin{array}{l}296 \\
356 \\
490 \\
384 \\
325\end{array}$ & $\begin{array}{l}13.5(38) \\
12.4(42) \\
14.6(68) \\
16.4(60) \\
21.7(67) \\
p<0.001\end{array}$ & $\begin{array}{l}1.08 \\
1.00 \\
1.10 \\
1.31 \\
1.57 \\
p=0.01\end{array}$ & $\begin{array}{l}1 \cdot 10 \\
1 \cdot 00 \\
1 \cdot 04 \\
1 \cdot 26 \\
1 \cdot 45 \\
p=0.07\end{array}$ & $\begin{array}{l}1 \cdot 11(0 \cdot 67,1 \cdot 66) \\
1 \cdot 00 \\
1 \cdot 02(0 \cdot 66,1 \cdot 58) \\
1 \cdot 20(0 \cdot 52,1 \cdot 30) \\
1 \cdot 38(0 \cdot 87,2 \cdot 10) \\
p=0 \cdot 10\end{array}$ \\
\hline Relative risk & & 1.67 & 1.46 & 1.35 & $1 \cdot 30$ & & $1 \cdot 46$ & $1 \cdot 40$ & $1 \cdot 30$ & 1.26 \\
\hline
\end{tabular}

(A) Adjusted for age, social class, smoking, physical activity, body mass index, lung function, and diabetes.

(B) Adjusted in addition for blood cholesterol.

(C) Adjusted in addition for systolic blood pressure. 


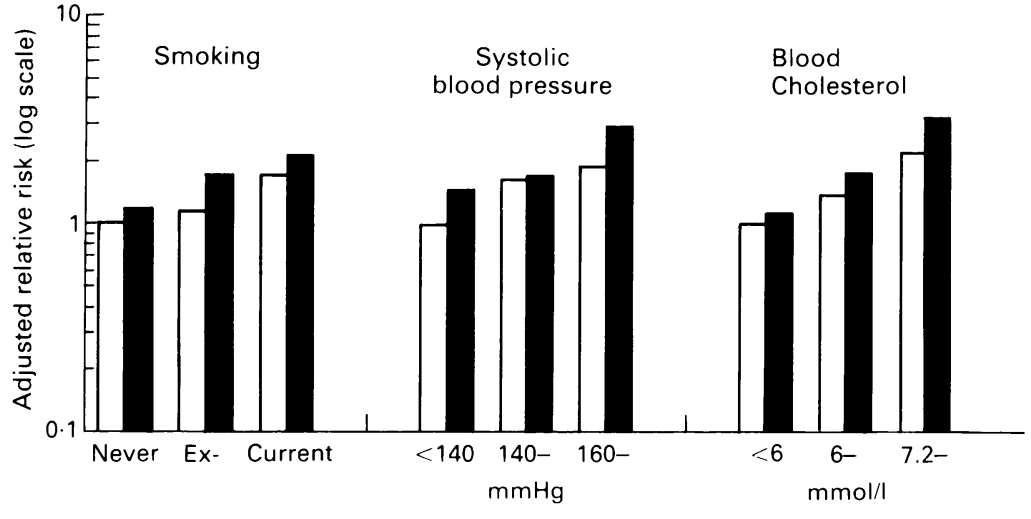

Low haematocrit

Figure 2 Raised haematocrit ( $\geqslant 46 \%$ ) and adjusted relative risk of major ischaemic heart disease (IHD) events in relation to smoking, systolic blood pressure, and blood cholesterol. Adjusted for age, social class, smoking, physical activity, body mass index, lung function, pre-existing IHD, diabetes and each of the other factors.

atocrit and the risk of IHD events. Haematocrit is significantly associated with total serum protein concentration $(\mathrm{r}=0 \cdot 18)$ and with its main components, albumin $(r=0 \cdot 13)$ and globulin $(r=0 \cdot 19)$. However, the total serum protein concentration showed no association with the risk of IHD events once age, smoking, blood pressure, blood cholesterol, and social class are taken into account. The relationship between haematocrit and risk of IHD is thus unaffected by adjustment for total serum protein concentration.

\section{Discussion}

In this study of middle-aged British men, a raised haematocrit $(\geqslant 46)$ was associated with an increase in risk of major IHD events independent of age, social class, body weight, physical activity, lung function, and pre-existing evidence of IHD. Although most studies have found a positive association between haematocrit and risk of heart attacks, ${ }^{5-12}$ many have found the relationship to be dependent on established coronary risk factors,${ }^{1012}$ in particular blood pressure and blood cholesterol. In this study haematocrit showed a strong positive association with both blood cholesterol and blood pressure. The positive association between haematocrit and blood pressure is well documented ${ }^{2223}$ and it is thought that a raised haematocrit predisposes to hypertension. If raised haematocrit does indeed produce a rise in blood pressure, then adjusting for blood pressure may not be appropriate, except to assess whether the relationship is mediated through blood pressure. Several studies have also noted a strong positive association between blood cholesterol and haematocrit and it is suggested that the association may be due to changes in plasma volume resulting in both a rise in blood cholesterol and in haematocrit levels. ${ }^{24-25}$ It has also been reported that cholesterol and triglycerides cause rigidification of erythrocytes because of metabolic relations between lipoprotein fractions and cell membrane, and this is likely to result in increased haematocrit. ${ }^{29}$ In the present study the positive relationship between haematocrit and major IHD events was reduced after adjusting for blood cholesterol in addition, but the relationship remained significant. Further adjustment for systolic blood pressure reduced the excess risk further but the risk still increased at levels of $46.0 \%$ or above. It is well established that the presence of IHD is associated with increased haematocrit levels. ${ }^{22-24}$ However, the positive relationship between haematocrit and the risk of heart attacks was seen in the present study even after exclusion of men with evidence of IHD. Indeed the relationship was similar in both men with and without IHD in that haematocrit levels $\geqslant 46.0 \%$ were associated with about a $30 \%$ increase in risk in both groups.

It is of some interest that the most noticeable effects of adjustments for blood cholesterol and for systolic blood pressure were seen at the highest levels of haematocrit $(\geqslant 48 \cdot 0 \%)$. Although some of the excess risk was due to raised systolic blood pressure, this did not account for all the excess risk seen. This implies that the mechanism in the haematocrit-IHD relationship is either to some extent independent of blood lipids and blood pressure or that the process of adjustment does not take into account the imprecision of the measured risk factors. ${ }^{30}$

\section{OTHER STUDIES}

Several studies have found the relationship between haematocrit and heart attacks to be dependent on blood cholesterol and systolic blood pressure. ${ }^{1012}$ In these studies a linear relationship has been assumed and multiple regression analyses have been used, fitting haematocrit as a continuous variable and assessing the significance of the trend after adjustment. In the present study, haematocrit was raised only at levels of $46.0 \%$ and beyond with no further increase at higher levels after adjustment for the established coronary risk factors. Furthermore, men with low haematocrit had a slight increase in risk after adjustment for cholesterol and blood pressure compared with those within the range $42 \cdot 0-45 \cdot 9 \%$. In one study, those with a low haematocrit have been shown to have a slight increase in risk of coronary heart disease mortality, ${ }^{7}$ so that assuming a linear relationship would flatten the trend, even though the risk might be significantly raised at higher levels of haematocrit. Nevertheless, the Puerto Rican Study ${ }^{7}$ found a significant positive association between haematocrit (fitted as a continuous variable) and risk of heart attacks even after adjustment for the established risk factors, and in the Stockholm Prospective Study, ${ }^{6}$ haemoglobin, which is highly correlated with haematocrit, was found to be significantly and independently associated with risk of myocardial infarction. A recent study which has used cut off points has found a significant relationship between a raised haematocrit $(\geqslant 46.0 \%)$ and the risk of heart attacks even after adjustment for the coronary risk factors. ${ }^{8}$ Raised haematocrit was associated with a twofold increase in the risk of heart attacks compared with those 
with lower levels. The positive association between a raised haematocrit and IHD has also been observed in women. In a study of 1438 women aged 45-74, a haematocrit level over $45.0 \%$ was associated with an increased risk of IHD mortality even after adjustment for smoking. No data were available on blood cholesterol or blood pressure. ${ }^{9}$

\section{BLOOD VISCOSITY}

Although the mechanism for the role of haematocrit in the development of atherosclerosis is uncertain, there is growing speculation that its effect may be via blood viscosity. ${ }^{910}$ Haematocrit is the strongest determinant of whole blood viscosity. ${ }^{3} \mathrm{~A}$ linear increase in haematocrit produces an exponential increase in blood viscosity, thereby reducing blood flow particularly at sites of vascular damage and low shear rate. The exponential nature of this association may provide an explanation for the non-linear shape of the relationship between haematocrit and IHD events. The adverse effect of raised haematocrit $(\geqslant 46 \%)$ within the normal reference range, as within the polycythaemic range, may be mediated via a viscosity induced reduction in blood flow.

Plasma viscosity, although less important as a determinant of whole blood viscosity than haematocrit, ${ }^{3}$ may also make an important contribution to cardiovascular risk. Fibrinogen is an important determinant of plasma viscosity, particularly at low shear rates, and is an independent predictor of cardiovascular events. ${ }^{31}$ Cigarette smoking is the major environmental determinant of the fibrinogen level and about half of the IHD risk in cigarette smokers can be attributed to their higher fibrinogen level. ${ }^{32}$ It is also suggested that fibrinogen variations within the levels encountered in the general population may reflect the activity and instability of the atherosclerotic plaque. ${ }^{33}$ However, a recent report from the Caerphilly study suggests that plasma viscosity has an influence on IHD risk which is independent from that of fibrinogen, although the conclusion is dependent on the precise adjustment used. ${ }^{4}$ Fibrinogen was not measured in this study and thus the independent contributions of haematocrit, plasma viscosity, and fibrinogen concentration to the IHD risk need to be examined further in longitudinal studies with data on all these factors.

\section{CONCLUSION}

This study suggests that a raised haematocrit plays a role in the development of major IHD. There was no difference in the risk of IHD at haematocrit levels within the range $42 \cdot 0-45 \cdot 9$ observed in population studies. At levels of $46.0 \%$ and beyond the risk of heart attacks increased. Some of the increased risk of IHD was associated with the established coronary risk factors but even after adjusting for these risk factors there still remained an independent effect of a raised haematocrit on the risk of major IHD events. This effect could be related to the imprecision with which the adjusted variables are measured, or it could be truly independent. The findings support the suggestion that blood rheology, of which the haematocrit is an important component, plays a part in the development of IHD.

The British Regional Heart Study is a British Heart Foundation Group and is also supported by the Department of Health and The Stroke Association. Haematocrit measurements were determined in the Department of Haematology, Queen Elizabeth Hospital, Birmingham, supported by the Department of Health. We thank Professor J Stuart for his valuable comments on the paper.

1 Chievitz E, Thiede T. Complications and causes of death in polycythaemia vera. Acta Med Scand 1962;172:513-23.

2 Wills RE, Merrill EW. Influence of flow properties of blood upon viscosity-haematocrit relationships. $\mathcal{f}$ Clin Invest 1962;41:1591-8.

3 de Simone G, Devereux RB, Chien S, et al. Relation of blood viscosity to demographic and physiologic variables and to cardiovascular risk factors in apparently normal adults. Circulation 1990;81:107-17.

4 Yarnell JWG, Baker IA, Sweetnam PM, et al. Fibrinogen, viscosity and white blood cell count are major risk factors for ischaemic heart disease: the Caerphilly and Speedwell Collaborative Heart Disease Studies. Circulation 1991;83:836-44.

5 Waters WE, Withey JL, Kilpatrick GS, Wood PHN, Abernethy $M$. Ten-year haematological follow-up: mortality and haematological changes. BMf 1969;4:761-4.

6 Carlson LA, Bottinger LE, Ahlfeld PE. Risk factors for myocardial infarction in the Stockholm Prospective Study. Acta Med Scand 1979;206:351-60.

7 Sorlie PD, Garcia-Palmieri MR, Costas RC, Havlik RJ. Hematocrit and risk of coronary heart disease: the Puerto Rico Heart Health Program. Am Heart $\mathcal{F}$ 1981;101:45661.

8 Knottnerus JA, Swaen GMH, Slangen JJM, Volovics A Durinck J. Haematologic parameters as risk factors for cardiac infarction, in an occupational health care setting. $\mathcal{F}$ Clin Epidemiol 1988;41:67-74.

9 Campbell MJ, Elwood PC, Mackean J, Waters WE. Mortality, haemoglobin level and haematocrit in women. $\mathcal{J}$ Chron Dis 1985;38:881-9.

10 Carter C, McGee D, Reed D, Yano K. Stemmerman G Hematocrit and the risk of coronary heart disease: the Honolulu Heart Program. Am Heart f 1983;105:674-9.

11 Cullen KJ, Stenhouse NS, Wearne KL. Raised haemoglobin and risk of cardiovascular disease. Lancet 1981;ii:1288-9 (letter).

12 Cullen K, Stenhouse NS, Wearne KL, Welborn TA. Multiple regression analysis of risk factors for cardiovascular disease and cancer mortality in Busselton, Western Australia-13-year Study. F Chron Dis 1983;36:371-7.

13 Abu-Zeid HA, Chapman JM. The relation between haemoglobin level and the risk for ischaemic heart disease: a prospective study. $\mathcal{F}$ Chron Dis 1976;29:395.

$14 \mathrm{McD}$ onough JR, Homes CG, Garrison GE, et al. The relationship of hematocrit to cardiovascular states of
health in the Negro and White population of Evans health in the Negro and White population

15 Shaper AG, Pocock SJ, Walker M, Cohen NM, Wale CJ, Thomson AG. British Regional Heart Study: cardiovascular risk factors in middle-aged men in 24 towns. $B M \mathcal{F}$ 1981;283:179-86.

16 Shaper AG, Wannamethee G. Physical activity and ischaemic heart disease in middle-aged British men. $\mathrm{Br} \mathrm{Hear}$ f 1991;66:384-94.

17 Bull BS, Elashoff RM, Heilbron DC, Couperus J. A study of various estimators for the derivation of quality control procedures from patient erythrocyte indices. Am $\mathcal{f}$ Clin Pathol 1974;61:473-81.

18 Bruce NG, Shaper AG, Walker M, Wannamethee G Observer bias in blood pressure studies. $\mathcal{f}$ Hypertens 1988;6:375-80.

19 Cook DG, Shaper AG, Macfarlane PW. Using the WHO (Rose) angina questionnaire in cardiovascular epidemiological studies. Int $\mathcal{F}$ Epidemiol 1989;18:607-13.

20 Walker M, Shaper AG. Follow-up of subjects in prospective studies based in general practices. $\mathcal{F} R$ Coll Gen Pract 1984;34:365-70.

21 Pocock SJ, Shaper AG, Phillips AN, Walker M, Whitehead TP. High density lipoprotein cholesterol is not a major risk factor for ischaemic heart disease in British men BMF 1989;292:515-19.

22 Fuchs J, Weinberger I, Rotenberg Z, et al. Plasma viscosity in ischaemic heart disease. Am Heart f 1984;108:435-9.

23 Burch GE, DePasquale NP. The hematocrit in patients with myocardial infarction. $\mathcal{F} A M A$ 1962;180:63-5.

24 Lowe GDO, Drummond DMD, Lorimer AR, et al. Relation between extent of coronary artery disease and blood lation between extent of coron
viscosity. $B M \mathcal{F} 1980 ; \mathrm{i}: 673-4$.

25 Tibblin G, Bergentz SE, Bjure J, et al. Hematocrit, plasma protein, plasma volume and viscosity in early hypertenprotein, plasma volume and viscosity in

26 Letcher RL, Chien S, Pickering TG, Sealey JE, Laragh JH. Direct relationship between blood pressure and blood viscosity in normal and hypertensive subjects. $\mathrm{Am} \mathcal{f} \mathrm{Med}$
visections viscosity in normal 
27 Bottinger LE, Carlson LA. Relation between serum cholesterol and triglyceride concentration and haemoglobin values in non-anaemic healthy persons. $B M F$ 1972;3:731-

28 Bottinger LE, Carlson LA. Haemoglobin, plasma lipids and coronary heart disease. Am Heart $\mathcal{f}$ 1973;86:842-4.

29 Ankelkort B, Kiesewetter $\mathrm{H}$. Influence of risk factors and coagulation phenomena on the fluidity of blood in chronic arterial occlusive disease. Scand $\mathcal{f}$ Clin Lab Invest 1981;41(Suppl 156):185-8.

30 Phillips AN, Davey-Smith G. How independent are "independent" effects? Relative estimation when correlated exposures are measured imprecisely. $f$ Clin Epidemiol $1991 ; 44: 1223-31$.

31 Meade TW, Brozovic M, Chakrabarti RR, et al. Haemostatic function and ischaemic heart disease: principal results of the Northwick Park Study. Lancet 1986;ii:533-7.

32 Meade TW, Imeson J, Stirling Y. Effects of changes in smoking and other characteristics on clotting factors and the risk of ischaemic heart disease. Lancet 1987;ii:986-8. 33 Kannel WB. The Framingham experience: coronary heart disease epidemiology. In: Marmot $M$, Elliott $P$, eds. Aetology to public health. Oxford: Oxford University Press, 1992:67-82. 